\title{
The impact of sepsis, delirium, and psychological distress on self-rated cognitive function in ICU survivors-a prospective cohort study
}

\author{
Emily Brück ${ }^{1,2^{*}}$ (D) Anna Schand1 ${ }^{1,3}$, Matteo Bottai ${ }^{4}$ and Peter Sackey ${ }^{1,2}$
}

\begin{abstract}
Background: Many intensive care unit (ICU) survivors develop psychological problems and cognitive impairment. The relation between sepsis, delirium, and later cognitive problems is not fully elucidated, and the impact of psychological symptoms on cognitive function is poorly studied in ICU survivors. The primary aim of this study was to examine the relationship between sepsis, ICU delirium, and later self-rated cognitive function. A second aim was to investigate the association between psychological problems and self-rated cognitive function 3 months after the ICU stay.
\end{abstract}

Methods: Patients staying more than $24 \mathrm{~h}$ at the general ICU at the Karolinska University Hospital Solna, Stockholm, Sweden, were screened for delirium with the Confusion Assessment Method-ICU (CAM-ICU) during their ICU stay. Sepsis incidence and severity were recorded. Three months later, 216 patients received the Cognitive Failures Questionnaire (CFQ), Hospital Anxiety and Depression Scale (HADS), and Post-Traumatic Stress Symptoms-10 (PTSS-10) questionnaires via postal mail.

Results: One hundred twenty-five patients (60\%) responded to all questionnaires. Among respondents, the incidence of severe sepsis or septic shock was $42 \%$. The overall incidence of delirium was 34\%. Patients with severe sepsis/septic shock had a higher incidence of delirium, with an odds ratio (OR) of 3.7 (95\% confidence interval (Cl), 1.7-8.1). Self-rated cognitive problems 3 months post-ICU were found in 58\% of the patients. We did not find any association between sepsis or delirium and late self-rated cognitive function. However, there was a correlation between psychological symptoms and self-rated cognitive function, with the strongest correlation between PTSS-10 scores and CFQ scores $(r=0.53 ; p<0.001)$.

Conclusions: ICU delirium is more common in severely septic/septic shock patients. In our cohort, neither severe sepsis nor ICU delirium was associated with self-rated cognitive function 3 months after the ICU stay. Ongoing psychological symptoms, particularly post-traumatic stress was associated with worse self-rated cognitive function. Psychological symptoms need to be taken into account when assessing cognitive function in ICU survivors.

Keywords: Critical care, Intensive care units, Delirium, Sepsis, Cognitive impairment, Post-traumatic stress symptoms, Anxiety, Depression

\footnotetext{
* Correspondence: Emily.bruck@sll.se

${ }^{1}$ Function Perioperative Medicine and Intensive Care, Karolinska University

Hospital Solna, 17176 Stockholm, Sweden

${ }^{2}$ Department of Physiology and Pharmacology, Karolinska Institutet,

Stockholm, Sweden

Full list of author information is available at the end of the article
} 


\section{Background}

A significant proportion of ICU survivors develops multiple complications, including cognitive impairment and psychological problems. Cognitive impairment can persist for a long time after critical illness, reducing healthrelated quality of life [1-3]. The reasons for cognitive impairment after critical illness are not fully understood, and many contributing factors have been suggested, including delirium $[4,5]$ and sepsis [6].

Delirium has been reported to occur in up to $30-80 \%$ of ICU patients [7]. The incidence and duration of delirium have been associated with prolonged hospitalization and increased mortality and morbidity [7-9] and been indicated as a risk factor for the development of later cognitive problems weeks to months after the ICU stay [10-12].

Sepsis occurs in one third of ICU patients [13], and mortality in patients with septic shock is high $[13,14]$. Besides carrying a high mortality rate, sepsis is associated with a significant burden of morbidities, such as multiple organ failure [15], critical illness myopathy, and acute delirium [16]. The association between sepsis, ICU delirium, and prolonged cognitive problems is not fully elucidated, and mechanisms between postulated links are not well understood.

In parallel, up to $20 \%$ of ICU survivors have clinically significant problems with anxiety, depression, and posttraumatic stress disorder (PTSD) in the year after critical illness [17, 18]. In non-ICU patients, post-traumatic stress and depressive problems have been associated with more cognitive problems compared to controls [19]. To our knowledge, the potential association between psychological sequelae after critical illness and late cognitive problems in ICU survivors has not been investigated previously.

The objectives of this study were twofold. The primary objective was to assess whether sepsis and delirium were associated with a worse self-rated 3-month cognitive function in a mixed ICU population. A second objective was to investigate if depressive, anxiety, or posttraumatic stress symptoms were associated with selfrated cognitive dysfunction 3 months after ICU stay.

\section{Methods}

\section{Study design}

This was a prospective observational study at Karolinska University Hospital, where part of the patient cohort was included in an international multicenter study (PREDELIRIC) [20, 21]. For the present study, patients were followed for 3 months. In order to reach a sufficient number of patients for power in the present study, data collection was prolonged after the PRE-DELIRIC study was ended. The study was approved by the Regional Ethical Review Board in Stockholm (Approval number 2012/35-31/2).

\section{Patients}

Patients with an ICU length of stay $>24 \mathrm{~h}$ at the general ICU, a mixed medical and surgical 13 beds, at Karolinska University Hospital in Solna, were eligible for this study. Patients who were mentally impaired (including dementia), had serious auditory or visual disorders, were unable to understand Swedish, or suffered from serious aphasia were excluded. Patients transferred to other ICUs were also excluded as the presence of or total duration of ICU delirium could not be assessed. Patients with a Richmond Agitation and Sedation Scale - 4 or more during their entire ICU stay were excluded, as it was not possible to perform delirium screening at any time.

As per ethical approval, patient consent to participation was obtained via postal mail at the time of questionnaire follow-up.

\section{Data collection}

Data were collected from January 2012 to February 2013. Patients were not assessed for the study in the weekends and in the summer months of June-August as research nurses were not present in these periods. Patient characteristics data (age, history of psychological problems, pre-existing cognitive problems, abuses of nicotine, drugs or alcohol, diabetes mellitus, history of vascular disease) and ICU-related information (use of corticosteroids, respiratory failure, and APACHE II score) were collected from the electronic patient data management system and through medical chart review.

\section{Assessment of delirium}

The general ICU nurses screened patients for delirium three times a day using the Confusion Assessment Method for the ICU (CAM-ICU) [22, 23], as per clinical routine. CAM-ICU has shown good validity for identifying delirium in critically ill patients [24]. Patients were classified of having delirium if they had at least one positive CAM-ICU during their ICU stay.

\section{Assessment of severe sepsis/septic shock}

The presence and severity of sepsis were identified using standard definitions at the time-systemic inflammatory response syndrome (SIRS) in response to an infectious process.

We used the definition for severe sepsis and septic shock to include patients into one group, as sepsis without organ dysfunction or shock is very common in the ICU, and we wanted to select patients with evidence of organ dysfunction, an approach that has become formalized since the outset of our study [25]. Severe sepsis/septic shock was defined as sepsis with severe organ failure (kidney failure, coagulopathy, respiratory failure, acidosis) or sepsis with the need of inotropic drugs to sustain adequate blood pressure (Table 1 ). 
Table 1 Clinical definitions of sepsis used in the study

\begin{tabular}{ll}
\hline Systemic inflammatory response syndrome (SIRS) & Two or more of the following: \\
& $\cdot$ Temperature $>38$ or $<36{ }^{\circ} \mathrm{C}$ \\
& $\cdot$ Heart rate $>90 / \mathrm{min}$ \\
& $\cdot$ Respiratory rate $>20 / \mathrm{min}$ \\
& $\cdot$ White blood cell count $>12 \times 10^{9}$ or $<4 \times 10^{9}$ \\
& SIRS and evidence of infection \\
Sepsis & At least one sign of sepsis-associated organ dysfunction, hypoperfusion or hypotension, including \\
Severe sepsis & lactate acidosis, oliguria, or acute alteration of mental state \\
& Severe sepsis with hypotension (systolic blood pressure $<90$ mmHg or a reduction from baseline \\
Septic shock & $>40 \mathrm{mmHg}$ ) refractory to adequate fluid resuscitations or need of inotropic drug
\end{tabular}

\section{Assessment of 3-month outcomes}

The 3-month outcomes were (1) self-rated cognitive function, (2) symptoms of post-traumatic stress, and (3) anxiety or depression.

(1) For self-rated cognitive function, the Cognitive Failures Questionnaire (CFQ) was used [26]. It consists of 25 questions covering four dimensions of cognition: memory, distraction, social blunders, and naming. Each response has a scale from 0 to 4 , where 0 is never and 4 very often, referring to how often the specific cognitive difficulty occurs per day. A total CFQ score above 25 implies clinically significant cognitive problems [27].

(2) Post-Traumatic Stress Symptoms Scale-10 (PTSS$10)$ is an instrument to assess PTSD-related symptoms and consists of 14 questions divided into two parts [28]. Part A (four questions) concerns traumatic memories, whereas part B (ten questions) concerns current posttraumatic stress symptoms. In part B, the symptoms are graded from "never" [1] to "always" [7]. Part B total score above 35 (maximum 70) indicates clinically significant post-traumatic stress symptoms [29]. The questionnaire is considered to be reliable and valid for assessing post-traumatic stress symptoms in former ICU patients [28].

(3) Hospital Anxiety and Depression Scale (HADS) is a questionnaire consisting of two subscales measuring patient's symptoms of anxiety and depression. A subscale score above 10 (maximum subscale score 21) indicates clinically significant problems [30]. HADS is a well-used and valid instrument for detecting symptoms of anxiety and depression [31, 32].

The questionnaires were sent by postal mail to the patients 3 months after ICU discharge. Non-responders received a reminder letter and a new set of questionnaires after 2 weeks.

\section{Statistics}

STATA version 14 (StataCorp, College Station, TX, USA) and GraphPad Prism version 6 (GraphPad Software, San Diego, CA, USA) were used for data analysis. Alpha level was set to $5 \%$. A priori sample size calculations based on a five-point difference in the CFQ

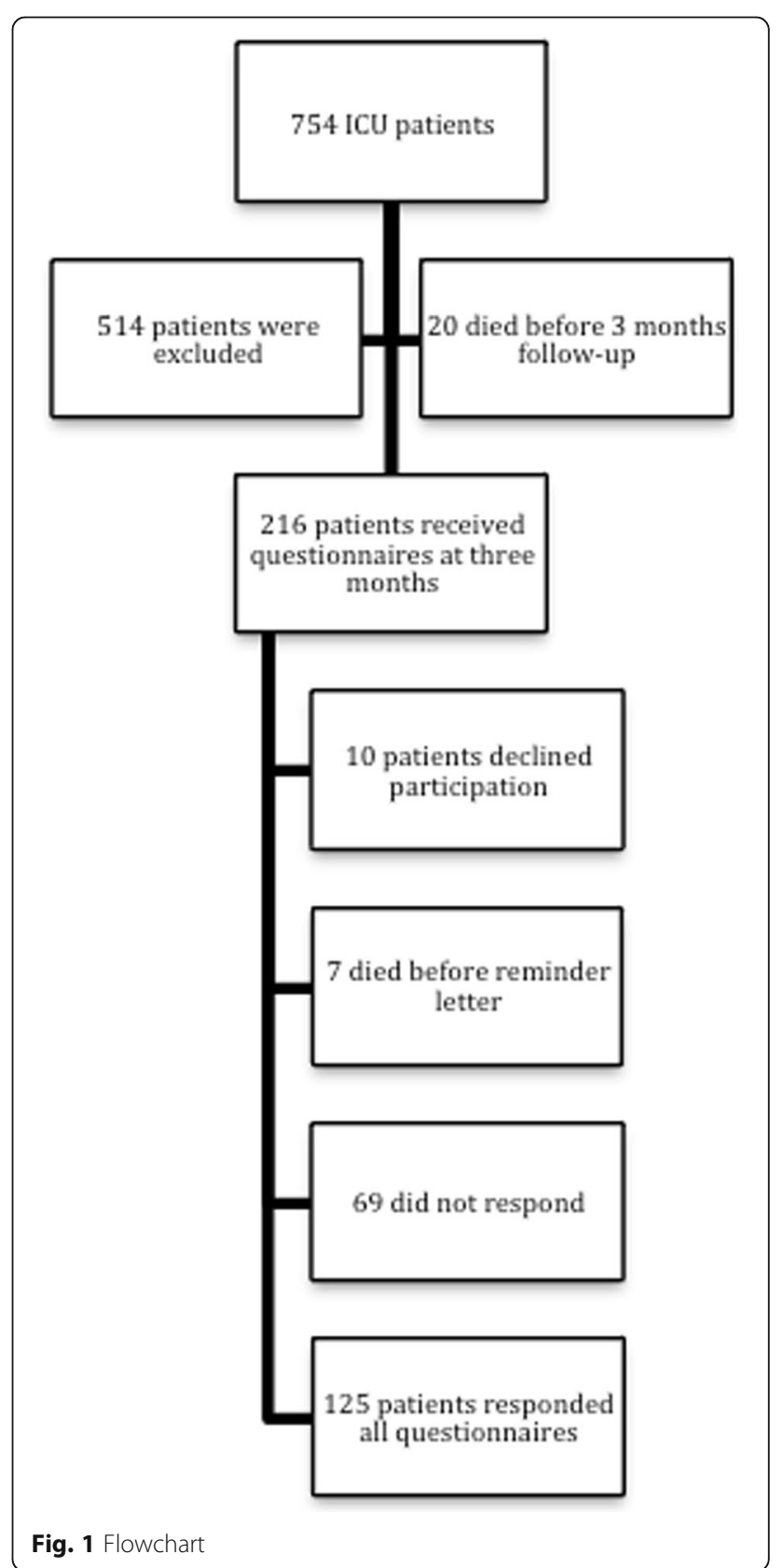


Table 2 Demographic characteristics of respondents

\begin{tabular}{lll}
\hline Variable & No sepsis, $n(\%)$ & Severe sepsis/septic shock, $n(\%)$ \\
\hline Age, median (IQR) in years & $62(42-73)$ & $63(50-73)$ \\
Men & $47(64)$ & $29(56)$ \\
History of cognitive disturbances & $4(5)$ & $3(6)$ \\
Alcohol, drug, or nicotine abuse & $15(20)$ & $16(31)$ \\
Diabetes mellitus & $8(11)$ & $8(15)$ \\
History of vascular disease & $14(19)$ & $8(15)$ \\
History of cardiac disease & $9(12)$ & $5(10)$ \\
APACHE II score, median (IQR) & $8(6-12)$ & $13(9-17)$ \\
Patient category & & $14(27)$ \\
$\quad$ Surgical & $34(47)$ & $29(56)$ \\
Medical & $28(38)$ & $9(17)$ \\
Trauma & $11(15)$ & \\
\hline
\end{tabular}

(standard deviation 10, power set to $80 \%$ ) between delirious and non-delirious patients rendered a needed sample size of 124 patients.

Demographic data were presented as medians and interquartile range. Questionnaire data were treated as ordinal. The association between severe sepsis and ICU delirium, including potential confounders, was assessed using logistic regression and presented as odds ratio (OR) with 95\% confidence intervals (CIs). Potential confounders were the severity of illness (APACHE II score), diabetes mellitus (present/not present), substance abuse (present/not present), and history of psychological problems (present/not present). Duration of ICU delirium was compared between patients ever or never having severe sepsis/septic shock with Student's $t$ test. The association between severe sepsis/septic shock, ICU delirium, and 3-month cognitive outcome (CFQ) was assessed using generalized estimating equations and presented as mean differences with $95 \% \mathrm{CI}$. The correlation between

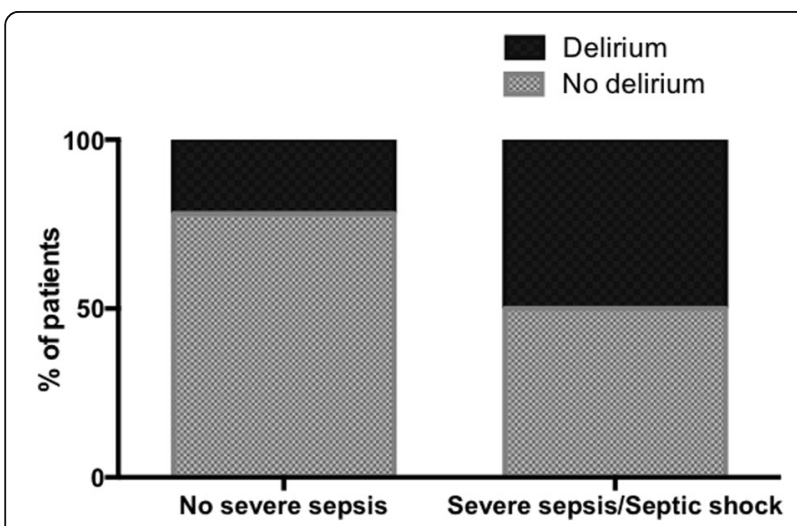

Fig. 2 Patients with severe sepsis/septic shock were more likely to develop delirium during the ICU stay (odds ratio 3.7 with 95\% confidence interval 1.7-8.1)
PTSS-10, HADS subscales, and CFQ was assessed with Spearman's rank correlation.

\section{Results}

Among 754 patients treated at the ICU during the study period, 216 patients received the questionnaires 3 months after ICU stay (Fig. 1). Seven patients died before the reminder letter. Of the remaining patients, 10 declined participation and 74 did not answer. One hundred twenty-five (60\%) responded to all three questionnaires. Demographic data for respondents are illustrated in Table 2.

\section{Severe sepsis/septic shock and delirium during the ICU stay}

Forty-two percent of the patients had severe sepsis/ septic shock. The overall incidence of ICU delirium was $34 \%$, with a significantly higher incidence in patients with severe sepsis/septic shock (Fig. 2), with a crude OR of 3.7 (95\% CI, 1.7-8.1), and with an adjusted OR of 2.9 (95\% CI, 1.2-7.2) (adjusted for APACHE II score, diabetes mellitus, substance abuse, history of psychological problems.)

The mean duration of ICU delirium (days) was longer in the severe sepsis/septic shock group than in the group

Table 3 Median (IQR) CFQ, PTSS-10, and HADS 3 months after ICU discharge

\begin{tabular}{lll}
\hline Questionnaire & $\begin{array}{l}\text { No severe sepsis/septic } \\
\text { shock }(n=73)\end{array}$ & $\begin{array}{l}\text { Severe sepsis/septic } \\
\text { shock }(n=52)\end{array}$ \\
\hline CFQ & $28(17-37)$ & $28(14-36)$ \\
PTSS-10 & $20(15-30)$ & $17(12-29)$ \\
HADS & $8(3-13)$ & $6(3-14)$ \\
$\quad$ Anxiety & $4(1-6)$ & $2(1-6)$ \\
$\quad$ Depression & $4(2-7)$ & $4(1-8)$ \\
\hline
\end{tabular}


Table 4 Mean differences (MDs) and 95\% confidence intervals (Cls) for the Cognitive Failure Questionnaire scores in patients with/ without severe sepsis/septic shock and delirium

\begin{tabular}{|c|c|c|}
\hline & \multicolumn{2}{|c|}{ Cognitive failure questionnaire score } \\
\hline & Crude model & Adjusted model $^{a}$ \\
\hline & MD $(95 \% \mathrm{Cl})$ & MD $(95 \% \mathrm{Cl})$ \\
\hline No severe sepsis/septic shock (reference) & 0 & 0 \\
\hline Severe sepsis/septic shock & $-1.73(-5.69$ to 2.23$)$ & $-2.76(-6.65$ to 1.12$)$ \\
\hline Delirium & $1.44(-2.69$ to 5.58$)$ & $0.61(-3.32$ to 4.54$)$ \\
\hline
\end{tabular}

ancluded variables in the adjusted model are history of vascular disease, alcohol abuse, history of psychological problems, and respiratory failure

without severe sepsis/septic shock $(1.17 \pm 0.22$ versus $0.45 \pm 0.13, p=.034)$.

\section{Severe sepsis/septic shock, ICU delirium, and cognitive function 3 months post-ICU}

Median CFQ scores (IQR) for patients without severe sepsis/septic shock and severe sepsis/septic shock were 28 [17-37] and 28 [14-36], respectively (Table 3). We did not find any association between the incidence of severe sepsis/septic shock or ICU delirium and later cognitive self-rated cognitive function (Table 4). We explored the possible interaction between sepsis and delirium without significant findings (data not shown).

\section{Psychological outcome and self-rated cognitive function 3 months post-ICU}

Fourteen percent of the respondents had PTSS-10 part B scores above 35. For HADS, the proportion of patients with an anxiety subscale score $>10$ was $14 \%$ and with a depression subscale score $>10$ was $13 \%$.

Patients with high scores in PTSS-10 part B had a worse self-rated cognitive function $(r=0.53 ; p<0.001)$
(Fig. 3). Similarly, there was a correlation between anxiety and depressive symptoms and self-rated cognitive dysfunction (HADS-a and CFQ $r=0.52 p<.001$; HADS$\mathrm{d}$ and CFQ $r=0.44 p<.001$ ) (Fig. 3).

\section{Discussion}

In this prospective observational study, patients with severe sepsis/septic shock had a higher incidence of ICU delirium. Neither severe sepsis/septic shock nor ICU delirium was associated with self-rated cognitive function 3 months after the ICU stay.

We found a significant correlation between the degree of psychological symptoms and self-rated cognitive function 3 months after ICU stay, with the strongest association between post-traumatic stress symptoms and cognitive function. To our knowledge, this is the first report on such an association in ICU survivors.

The potential link between acute and longer-term brain dysfunction in ICU survivors has been investigated in other studies [10-12, 33]. In a study by van den Boogaard et al., with a median follow-up period of 18 months, only small differences between patients with
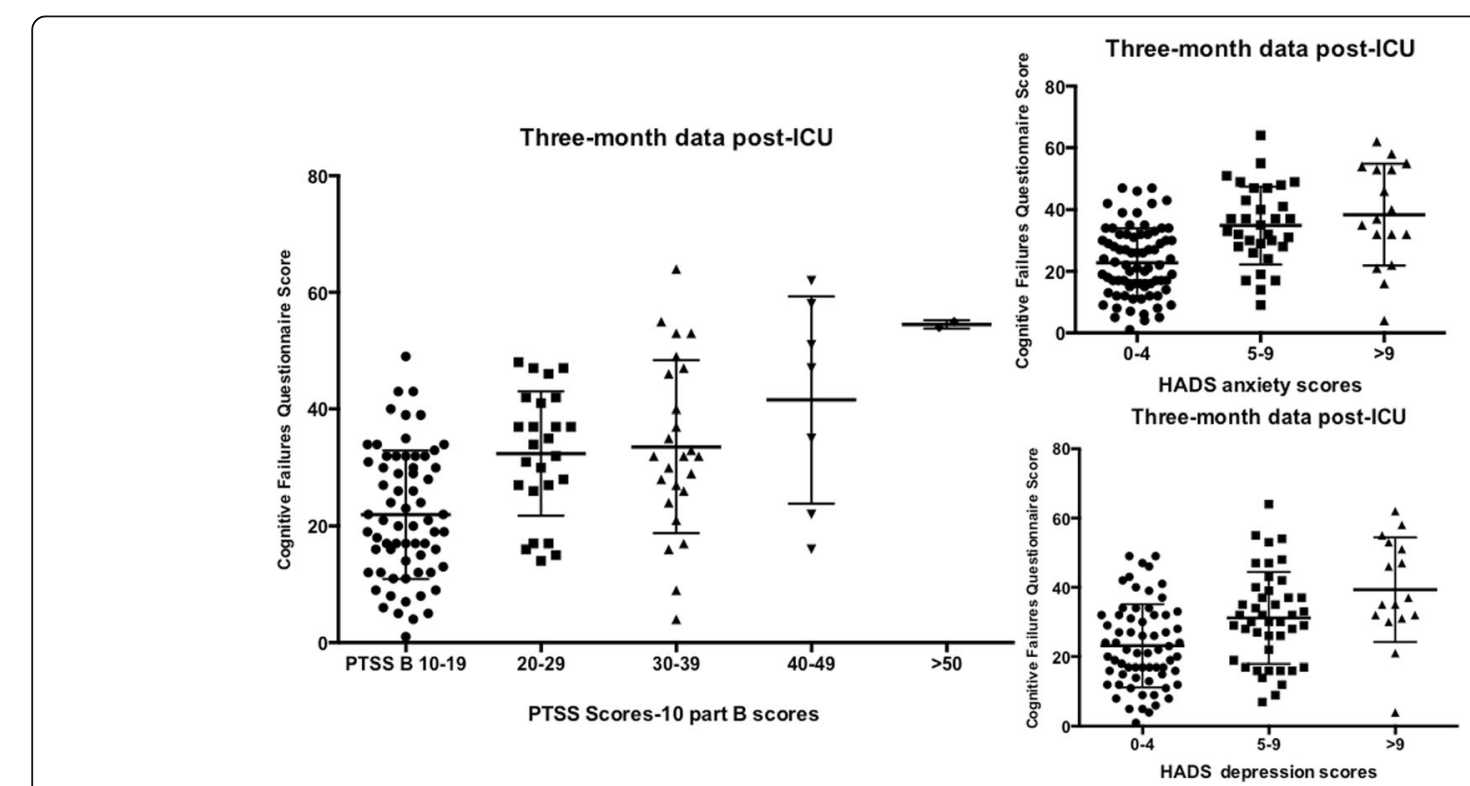

Fig. 3 Rating scores on the PTSS-10, HADS-a, and HADS-d, respectively, and CFQ. Lines and bars indicate median values and 25th and 75th percentiles 
and without delirium were found. In the cognitive follow-up study of ICU survivors by Pandharipande et al., the incidence of delirium was not associated with long-term cognitive outcome [11]. The authors found a correlation when the duration of hospital delirium was included in the analysis, a parameter that implied monitoring beyond the ICU stay, which is not routine in our hospital and not part of our study protocol.

Clinical definitions of sepsis have been reviewed recently with a focus on clinical severity [34]. While some studies indicate an association between sepsis and cognitive function, in the short and longer term [6,12], it may be that simple clinical definitions are not sufficiently specific for later cognitive manifestations of severe infection. Future research may possibly identify other early markers of septic encephalopathy or finer predictors of later cognitive problems associated with sepsis $[35,36]$.

As stated, we found significant correlations between the degree of psychological symptoms and self-rated cognitive dysfunction, with the strongest correlation between post-traumatic stress and cognitive dysfunction.

To our knowledge, this has never been described or accounted for in an ICU survivor cohort before. The findings are in line with studies from non-ICU patient populations, describing a link between psychological distress and cognitive dysfunction [37-39] This has been shown also in patients without apparent somatic injury [40]. Thus, it may be likely that cognitive impairment after critical illness might at least in part be mediated via emotional modulation and not necessarily via somatic illness or neurotrauma. Considering the symptomatology of post-traumatic stress that includes sleeping problems, hyperarousal, and concentration difficulties, it is plausible that patients with post-traumatic stress symptoms would have impaired cognitive function.

In light of the relatively high proportion of ICU survivors that suffer from psychological problems such as PTSD, depression, and anxiety [17, 18], we suggest that psychological state be assessed and accounted for when investigating and reporting cognitive outcomes after critical illness. Further, a clinically important research question arises-can PTSD treatment or prophylaxis in distressed ICU survivors improve their cognitive function?

\section{Limitations}

Our study has several limitations. The questionnaire response rate was $60 \%$, similar to that of many ICU follow-up studies. A higher response rate would have been desirable. However, participation was voluntary, and as per ethical approval, the offer to patients to participate and consent was given with the questionnaires.
This study was conducted before the introduction of the most recent sepsis definition $[34,41]$. The present definition requires organ dysfunction, with an increase in Sequential Organ Failure Assessment (SOFA) score of 2 points or more. We did not assess SOFA score. However, our priori approach, using only severe sepsis and septic shock, as "cases" is likely a closer approximation to the new definition, with sicker patients compared to a more liberal approach that would include all patients that simply fulfilled sepsis criteria.

Another limitation is the lack of baseline cognitive function, as most patients were emergency admissions, precluding such assessment.

It is also important to recognize that the CFQ is not a formal neuropsychological test [27]. However, the fact that CFQ is a self-rated test means it measures cognitive complaints patients experience in their everyday life, which is a relevant patient outcome.

\section{Conclusions}

In our cohort, neither severe sepsis nor ICU delirium was associated with self-rated cognitive function 3 months after the ICU stay. Ongoing psychological symptoms, particularly post-traumatic stress, were associated with worse self-rated cognitive function. This finding has implications on the interpretation and understanding of cognitive function after critical illness and ICU stay. Psychological screening is warranted in parallel with cognitive function assessment in ICU survivors.

\section{Abbreviations}

CAM-ICU: Confusion Assessment Method-ICU; CFQ: Cognitive Failures Questionnaire; HADS: Hospital Anxiety and Depression Scale; ICU: Intensive care unit; IQR: Interquartile range; PTSD: Post-traumatic stress disorder; PTSS10: Post-Traumatic Stress Symptoms Checklist-10

\section{Acknowledgements}

None.

\section{Funding}

Funding supported by grants provided by the Stockholm County Council (ALF), the Olle Byggmästare Foundation, and the Department of Perioperative Medicine and Intensive Care, Karolinska University Hospital Stockholm, Sweden.

\section{Availability of data and materials}

The datasets used and analyzed during the current study are available from the corresponding author on reasonable request.

\section{Authors' contributions}

EB performed the data collection and data analyses and was responsible for the manuscript writing. AS contributed to the study design, data analysis, and manuscript writing. MB contributed to the statistical analyses and reviewed the manuscript. PS contributed to the study design, data analysis, and manuscript writing. All authors read and approved the final manuscript.

Ethics approval and consent to participate

The study was approved by the Karolinska Institutet Regional Ethics Review Board in Stockholm, Sweden, approval number 2012/35-31/2.

Consent for publication

All participants gave informed consent. 


\section{Competing interests}

The authors declare that they have no competing interests.

\section{Publisher's Note}

Springer Nature remains neutral with regard to jurisdictional claims in published maps and institutional affiliations.

\section{Author details}

${ }^{1}$ Function Perioperative Medicine and Intensive Care, Karolinska University Hospital Solna, 17176 Stockholm, Sweden. ${ }^{2}$ Department of Physiology and Pharmacology, Karolinska Institutet, Stockholm, Sweden. ${ }^{3}$ Department of Molecular Medicine and Surgery, Karolinska Institutet, Stockholm, Sweden. ${ }^{4}$ The Unit of Biostatistics, Institute of Environmental Medicine, Karolinska Institutet, 17177 Stockholm, Sweden.

\section{Received: 12 October 2017 Accepted: 14 December 2017}

\section{Published online: 08 January 2018}

\section{References}

1. Cuthbertson BH, Scott J, Strachan M, Kilonzo M, Vale L. Quality of life before and after intensive care. Anaesthesia. 2005;60(4):332-9.

2. Oeyen SG, Vandijck DM, Benoit DD, Annemans L, Decruyenaere JM. Quality of life after intensive care: a systematic review of the literature. Crit Care Med. 2010;38(12):2386-400

3. Herridge MS, Cheung AM, Tansey CM, Matte-Martyn A, Diaz-Granados N, AlSaidi $\mathrm{F}$, et al. One-year outcomes in survivors of the acute respiratory distress syndrome. N Engl J Med. 2003;348(8):683-93.

4. Pandharipande $P$, Jackson J, Ely EW. Delirium: acute cognitive dysfunction in the critically ill. Curr Opin Crit Care. 2005;11(4):360-8.

5. Saczynski JS, Marcantonio ER, Quach L, Fong TG, Gross A, Inouye SK, et al. Cognitive trajectories after postoperative delirium. N Engl J Med. 2012; 367(1):30-9.

6. Iwashyna TJ, Ely EW, Smith DM, Langa KM. Long-term cognitive impairment and functional disability among survivors of severe sepsis. JAMA. 2010; 304(16):1787-94

7. Thomason JW, Shintani A, Peterson JF, Pun BT, Jackson JC, Ely EW. Intensive care unit delirium is an independent predictor of longer hospital stay: a prospective analysis of 261 non-ventilated patients. Crit Care. 2005;9(4): R375-81.

8. Ely EW, Shintani A, Truman B, Speroff T, Gordon SM, Harrell FE, et al. Delirium as a predictor of mortality in mechanically ventilated patients in the intensive care unit. JAMA. 2004;291(14):1753-62.

9. Lin SM, Liu CY, Wang CH, Lin HC, Huang CD, Huang PY, et al. The impact of delirium on the survival of mechanically ventilated patients. Crit Care Med. 2004:32(11):2254-9.

10. van den Boogaard M, Schoonhoven L, Evers AW, van der Hoeven JG, van Achterberg T, Pickkers P. Delirium in critically ill patients: impact on longterm health-related quality of life and cognitive functioning. Crit Care Med. 2012:40(1):112-8.

11. Girard TD, Jackson JC, Pandharipande PP, Pun BT, Thompson JL, Shintani AK, et al. Delirium as a predictor of long-term cognitive impairment in survivors of critical illness. Crit Care Med. 2010;38(7):1513-20.

12. Pandharipande PP, Girard TD, Jackson JC, Morandi A, Thompson JL, Pun BT, et al. Long-term cognitive impairment after critical illness. N Engl J Med. 2013;369(14):1306-16.

13. Vincent JL, Taccone F, Schmit X. Classification, incidence, and outcomes of sepsis and multiple organ failure. Contrib Nephrol. 2007;156:64-74.

14. Kaukonen KM, Bailey M, Suzuki S, Pilcher D, Bellomo R. Mortality related to severe sepsis and septic shock among critically ill patients in Australia and New Zealand, 2000-2012. JAMA. 2014:311(13):1308-16.

15. Deitch EA. Multiple organ failure. Pathophysiology and potential future therapy. Ann Surg. 1992;216(2):117-34

16. Ebersoldt M, Sharshar T, Annane D. Sepsis-associated delirium. Intensive Care Med. 2007;33(6):941-50

17. Davydow DS, Gifford JM, Desai SV, Needham DM, Bienvenu OJ. Posttraumatic stress disorder in general intensive care unit survivors: a systematic review. Gen Hosp Psychiatry. 2008;30(5):421-34.

18. Davydow DS, Gifford JM, Desai SV, Bienvenu OJ, Needham DM. Depression in general intensive care unit survivors: a systematic review. Intensive Care Med. 2009;35(5):796-809
19. Cohen BE, Neylan TC, Yaffe K, Samuelson KW, Li Y, Barnes DE. Posttraumatic stress disorder and cognitive function: findings from the mind your heart study. J Clin Psychiatry. 2013;74(11):1063-70.

20. van den Boogaard M, Pickkers P, Slooter AJ, Kuiper MA, Spronk PE, van der Voort PH, et al. Development and validation of PRE-DELIRIC (PREdiction of DELIRium in ICu patients) delirium prediction model for intensive care patients: observational multicentre study. BMJ. 2012 344:e420.

21. van den Boogaard M, Schoonhoven L, Maseda E, Plowright C, Jones C, Luetz A, et al. Recalibration of the delirium prediction model for ICU patients (PRE-DELIRIC): a multinational observational study. Intensive Care Med. 2014:40(3):361-9.

22. Ely EW, Inouye SK, Bernard GR, Gordon S, Francis J, May L, et al. Delirium in mechanically ventilated patients: validity and reliability of the confusion assessment method for the intensive care unit (CAM-ICU). JAMA. 2001; 286(21):2703-10

23. Ely EW, Margolin R, Francis J, May L, Truman B, Dittus R, et al. Evaluation of delirium in critically ill patients: validation of the Confusion Assessment Method for the Intensive Care Unit (CAM-ICU). Crit Care Med. 2001;29(7): 1370-9.

24. Gusmao-Flores D, Salluh I, Chalhub RA, Quarantini LC. The confusion assessment method for the intensive care unit (CAM-ICU) and intensive care delirium screening checklist (ICDSC) for the diagnosis of delirium: a systematic review and meta-analysis of clinical studies. Crit Care. 2012;16(4):R115.

25. Vincent JL, Opal SM, Marshall JC, Tracey KJ. Sepsis definitions: time for change. Lancet. 2013;381(9868):774-5.

26. Broadbent DE, Cooper PF, FitzGerald P, Parkes KR. The Cognitive Failures Questionnaire (CFQ) and its correlates. Br J Clin Psychol. 1982:21(Pt 1):1-16.

27. Bridger RS, Johnsen S, Brasher K. Psychometric properties of the Cognitive Failures Questionnaire. Ergonomics. 2013:56(10):1515-24.

28. Stoll C, Kapfhammer HP, Rothenhäusler HB, Haller M, Briegel J, Schmidt M, et al. Sensitivity and specificity of a screening test to document traumatic experiences and to diagnose post-traumatic stress disorder in ARDS patients after intensive care treatment. Intensive Care Med. 1999;25(7):697-704.

29. Nickel M, Leiberich P, Nickel C, Tritt K, Mitterlehner F, Rother W, et al. The occurrence of posttraumatic stress disorder in patients following intensive care treatment: a cross-sectional study in a random sample. J Intensive Care Med. 2004;19(5):285-90.

30. Zigmond AS, Snaith RP. The hospital anxiety and depression scale. Acta Psychiatr Scand. 1983;67(6):361-70.

31. Lisspers J, Nygren A, Soderman E. Hospital Anxiety and Depression Scale (HAD): some psychometric data for a Swedish sample. Acta Psychiatr Scand. 1997:96(4):281-6.

32. Bjelland I, Dahl AA, Haug TT, Neckelmann D. The validity of the Hospital Anxiety and Depression Scale. An updated literature review. J Psychosom Res. 2002;52(2):69-77.

33. Wolters $A E$, van Dijk D, Pasma W, Cremer OL, Looije MF, de Lange DW, et al. Long-term outcome of delirium during intensive care unit stay in survivors of critical illness: a prospective cohort study. Crit Care. 2014;18(3):R125

34. Singer M, Deutschman CS, Seymour CW, Shankar-Hari M, Annane D, Bauer $M$, et al. The Third International Consensus Definitions for Sepsis and Septic Shock (Sepsis-3). JAMA. 2016;315(8):801-10.

35. Chavan SS, Huerta PT, Robbiati S, Valdes-Ferrer SI, Ochani M, Dancho M, et al. HMGB1 mediates cognitive impairment in sepsis survivors. Mol Med. 2012;18:930-7

36. Widmann CN, Heneka MT. Long-term cerebral consequences of sepsis. Lancet Neurol. 2014:13(6):630-6.

37. Hohman TJ, Beason-Held LL, Resnick SM. Cognitive complaints, depressive symptoms, and cognitive impairment: are they related? J Am Geriatr Soc. 2011;59(10):1908-12

38. Qureshi SU, Long ME, Bradshaw MR, Pyne JM, Magruder KM, Kimbrell T, et al. Does PTSD impair cognition beyond the effect of trauma? J Neuropsychiatry Clin Neurosci. 2011;23(1):16-28.

39. Schuitevoerder S, Rosen JW, Twamley EW, Ayers CR, Sones H, Lohr JB, et al. A meta-analysis of cognitive functioning in older adults with PTSD. J Anxiety Disord. 2013;27(6):550-8.

40. Vasterling الر Duke LM, Brailey K, Constans Illain AN, Sutker PB. Attention, learning, and memory performances and intellectual 
resources in Vietnam veterans: PTSD and no disorder comparisons. Neuropsychology. 2002;16(1):5-14.

41. Shankar-Hari M, Phillips GS, Levy ML, Seymour CW, Liu VX, Deutschman CS, et al. Developing a new definition and assessing new clinical criteria for septic shock: for the Third International Consensus Definitions for Sepsis and Septic Shock (Sepsis-3). JAMA. 2016;315(8):775-87.

Submit your next manuscript to BioMed Central and we will help you at every step:

- We accept pre-submission inquiries

- Our selector tool helps you to find the most relevant journal

- We provide round the clock customer support

- Convenient online submission

- Thorough peer review

- Inclusion in PubMed and all major indexing services

- Maximum visibility for your research

Submit your manuscript at www.biomedcentral.com/submit 